\title{
ПРИЁМЫ ЭВРИСТИЧЕСКОГО ОБУЧЕНИЯ ПРИ ИЗУЧЕНИИ ИНТЕРАКЦИИ ЯЗЫКА И КУЛЬТУРЫ
}

Токарева И. Ю. Прийоми евристичного навчання при вивченні інтеракції мови та культури.

У статті розглядаються прийоми евристичного навчання, які можна застосувати при формуванні лінгвокультурологічної компетенції школярів.

Ключові слова: лінгвокультурологічна компетенція, мова, культура, навчання.

Токарева И. Ю. Приёмы эвристического обучения при изучении интеракции языка и культуры.

В статье рассматриваются приёмы эвристического обучения, которые можно применить при формировании лингвокультурологоической компетенции школьников.

Ключевые слова: культурно языковая компетенция, язык, культура, обучение.

Tokareva I. U. Receptions of heuristic traning at studyng of interaction of language and culture.

In article receptions of heuristic training which can be applied at formation linguistic-culturalism the competence of schoolboys are considered.

Key words: cultural language competence, language, culture, training.

Как было сказано ранее, основными методами, на которые опирается методика эвристического обучения, является проблемный и частичнопоисковый. Рассмотрим основные методические приёмы и формы, которые может использовать учитель при создании проблемной ситуации.

К эвристическим формам образовательной деятельности относятся: уроки, олимпиады, погружения, ролевые игры, проекты и др. Определим их особенности. Эвристический урок включает в себя задания, учитывающие лингвокультурологическую интерпретанту. Например, 1) Рассмотрите очертания букв кириллиџь. На каких трёх геометрических фигурах построены очертания букв? Что символизировали эти фигуры?; 2) Приведите примеры каламбуров. Можно ли их перевести на другой язык? Сделайте вывод; 3) Как вам известно, неконечные русские слоги строятся по закону открытого слога. Можно ли этот факт связать с особенностями русского ландшафта, 
бескрайними равнинами, отражающими певучесть, восходящий рисунок русской интонации?

Эвристическое погружение - форма обучения, при которой в течение нескольких дней сохраняется образовательная доминанта, обеспечивающая личностное познание учениками образовательного объекта с помощью эвристических методов обучения. Погружение происходит в определенную историческую эпоху, в произведение, в национальную культуру. Как правило, эвристическое погружение состоит из серии образовательных ситуаций. Так, учитель может предложить учащимся познакомиться с текстом «Повести временных лет», погрузиться в историческую эпоху и ответить на вопросы. Почему князь Владимир выбрал греческую религию? Что его оттолкнуло в других религиях? Учитыввал ли князь Владимир мировоззрение русских, особенности их жизнеустройства?

Творческие задания могут отличаться по типу, объему, времени их выполнения. Методика формирования культурно-языковой компетенции включает задания по интерпретации языковых фактов, эксперименты с культурно маркированными единицами, моделирование, сопоставление явлений разных языков, написание сочинений на лингвокультурологические темы.

При разработке заданий учитель может использовать ряд приёмов. Приём вживания в предмет изучения. Так, для активизации познавательной деятельности учитель может предложить учащимся представить себя иностранцами, приехавшими в Россию, посмотреть иными глазами на привычные явления. Рождающиеся при этом мысли, ощущения и есть эвристический образовательный продукт ученика.

Приёмы изучения и комментирования внутренней формы знака. О сильном дожде русские говорят: льёт как из ведра. В английском и немецком языке также имеются фразеологизмы, обозначающие сильный дождь. Если буквально, пословно перевести немецкий и английский фразеологизмы, соответствующие русскому, получим - дождь льёт как на дохлую собаку, дождь идёт кошками и собаками. Таким образом, одна и та же мысль в разных языках может быть представлена по-разному. Как вы думаете, почему? Сделайте вывод о том, можно ли фразеологизмы переводить на другой язык.

Приёмы выдвижения гипотезы. Например, что бы было, если в русском языке отсутствовали заимствования.

Приёмы гиперболизации. Например, придумайте максимальное число ласкательных вариантов вашего имени.

При решении проблемной задачи учителю рекомендуется использовать приёмы мозгового штурма. Основной задачей здесь является сбор как можно большего числа идей в результате освобождения учащихся от инерции мышления и стереотипов. Эвристический подход культивирует 
право на личные трактовки положений дел. Учащиеся анализируют проблемную ситуацию, затем генерируют идеи, дают им оценку, систематизируют. Окончательно отбираются только те идеи, которые не были отвергнуты критическими замечаниями и контридеями.

Одним из распространённых приёмов является изложение различных точек зрения на один и тот же вопрос. Приведём пример использования данного приёма.

Прочитайте мнения двух учёных-лингвистов о заимствованиях.

Ф. А. Литвин пишет: "...Призывы к спасению русского языка исходят из неверия в его жизнеспособность... Напротив, из предыдущего опьлта следует, что русский язык «вынесет всё, что Господь ни пошлёт».

А. С. Шииков был ярым противником заимствований. Он предлагал, чтобы все заимствования были бы заменень русскими словами. Например, предложение Франт идёт из циикка в театр по бульвару в калошах, по его мнению, следовало заменить на Хорошилище грядёт по гульбищу из ристалищца на позорище в мокроступах.

Дж. Свифт писал: «...Но более всего я желаю, чтобы обдумали способ установить и закроить наш язык навечно, после того как будут внесены в него те изменения, какие сочтут необходимыми. Ибо, по моему мнению, лучше языку не достичь полного совершенства, нежели постоянно изменяться. И мы должны остановиться, в противном случае наш язык в конце концов неизбежно изменится к худшему».

С каким из них вы согласны, а может, не согласны ни с одним? Можно ли обойтись без заимствований. Согласитесь ли вы с мыслью, что заимствования удовлетворяют мыслительные потребности человека, то есть помогают ему глубже понять что-то, выразить свою мысль, что заимствования заполняют пустые клеточки в той или иной языковой картине мира?

Учитель может побудить обучаемых делать сравнения, сопоставления, обобщения, выводы. Приведём пример такого задания.

Заполните пустые клетки таблицы. Сделайте вывод о несоответствии значений языковых эталонов во вьетнамском и русском языках.

$\begin{array}{ccc}\text { Слово - языковой эталон. } & \text { Значение языкового эталона во } & \text { Значение языкового } \\ \text { Свинья } & \text { вьетнамском языке } & \text { эталона в русском языке } \\ \text { Медведь } & \text { «глупость» } & \\ & \text { «наглость» }\end{array}$

Учитель подводит учащихся к проблеме и сам предлагает путь её решения. В некоторых проблемных задачах применение знаний выступает как результат решения. Это задачи поисковые, требующие отвлечения от ранее усвоенных способов решения, нахождения новых, умения вести поиск в разных направлениях. При решении творческой задачи учащиеся совершают для себя открытие. Примером такой задачи может быть 
лингвокультурологическая интерпретация лексического значения с опорой на когнитивные команды-операторы.

В ходе решения проблемной ситуации учащийся должен усвоить новые знания, но при этом предлагаемые задания всегда основываются на уже известных. Выполнение учебных задач всегда завершается фазой контроля и корректировки.

Эффективной для лингвокультурологических приращений будет и система нестандартных развивающих заданий, разработанная И. М. Подгаецкой, среди которых выделяются опознавательные (предполагающие узнавание тех или иных явлений), объяснительные (предусматривающие объяснение фактов), занимательные (синтезирующие задачи, которые решаются двумя предыдущими типами заданий. Так, при изучении языковых эталонов и символов учащимся предлагаются задания из ряда слов найти языковой символ или эталон, в процессе рассмотрения переносных значений учащиеся выполняют задания по комментированию выбора того или иного образа. Предлагаемая методика включает ряд занимательных упражнений. Например, на уроке повторения и закрепления знаний по теме «Лексика» ученикам предлагается написать плач, заклинание с использованием языковых символов и эталонов.

Методика формирования культурно-языковой компетенции личностно-ориентирована. Это означает, что функция учителя сводится к роли организатора самостоятельной активной познавательной деятельности учащихся. Деятельность учителя направлена не столько на контроль знаний и умений, сколько на диагностику деятельности учеников, чтобы правильно организовать процессы познания деятельности учащихся. Такой подход к обучению получил название холистического в трудах Р. Миллера и Дж. Макса Винго. Основной идеей этого подхода является концентрация внимания педагога на целостной личности человека, забота о развитии не только его интеллекта, гражданского чувства ответственности, но и духовной личности с эмоциональными, эстетическими, творческими задатками и возможностями развития. Очевидно, что при личностно-ориентированном обучении учитель учитывает особенности психического склада ребёнка, его характера и темперамента.

Задания позволяют интегрировать уроки русского языка с уроками литературы, истории, мировой художественной культуры, изобразительного искусства, музыки, иностранного языка. Так, при изучении тем «Антонимы. Типы антонимов. Антонимический ряд. Способы образования антонимов. Словари антонимов. Функции антонимов в речи», «Тематические группы слов» учащимся предлагается сравнить языковые единицы русского и иностранных языков.

Сложность, новизна, а подчас и малодоступность материала определяют активное использование таких приёмов, как рассказ, лекция, 
беседа и др. Данные приёмы позволяют учителю передать большой объём новой информации, а ученику получить систематизированное изложение данного вопроса. Учебники русского языка не изобилуют материалами лингвокультурологического характера. Теоретические обобщения отсутствуют вовсе. Закрыть эту брешь может только информация, исходящая из уст учителя. При составлении лекции учителю следует придерживаться принципа доступности, теоретические положения не должны быть перегружены, их следует хорошо иллюстрировать примерами. Данные формы работы нельзя воспринимать как уменьшающие активность учащихся. Диалоговая форма изложения, проблемные вопросы, интересные примеры активизируют познавательную деятельность учеников. Рассказ может быть применён на всех этапах урока. Он может играть роль вступления, заключения. Характер материала - раскрытие сущности взаимодействия языка и культуры - заставляет учителя вскрывать закономерности, причинно-следственные связи, существенные черты явления, что придаёт изложению характер объяснения. Изложение материала может осуществляться индуктивным (от рассмотрения конкретного примера) или дедуктивным (от теоретических положений) методами.

Изложение материала может проходить в виде демонстрации способов интерпретации лингвистического явления в категориях культуры. Каждая из целей, отражающих этапы обучения, достигается определённым набором приёмов. Для того чтобы обеспечить понимание, целесообразно использовать беседу, рассказ, разъяснение нового, выражение неизвестного через известное, привязку новых знаний к старым. Так, ведущая роль этим приёмам отводится при изучении темы «Что изучает лексика», темы «Что такое образное основание», где учитель рассказывает о том, что лексика отражает жизнь, мысли, чувства народа, вводит понятия мировосприятие, миропонимание, картина мира, культура, образное основание; демонстрирует, как связано образное основание с мировосприятием. К перечисленным приёмам мы прибегаем в тех случаях, когда учебный материал отличается новизной, теоретической сложностью, неосвещённостью в учебной литературе.

Запоминание достигается повторением, заучиванием. Так, при изучении темы «Слово и фразеологизм. Употребление фразеологизмов в речи» учитель предлагает учащимся вспомнить рассмотренные на прошлом уроке понятия.

Применение знаний по правилу предполагает выполнение упражнений. Например, при подготовке к написанию сочинения «О чём мне поведало значение слова или фразеологизма» учащиеся применяют свои знания по правилу (образцу) лингвокультурологической интерпретации значения. 
Применение знаний в новых условиях предполагает постановку проблемы, творческие задания разного типа, решение задач на новом материале, усложнение задач, выполнение нетиповых заданий. Так, при изучении темы «Многозначное слово. Прямое и переносное значение» учащиеся знакомятся с понятиями языковой символ и языковой эталон, после чего классу предлагаются задания найти слова-эталоны и символы, сопоставить языковые эталоны вьетнамского и русского языков, определить взаимосвязь количества значения многозначного слова со степенью ценности обозначаемого им понятия.

Ещё одним способом развития культурно-языковой компетенции является работа над проектом. В методической литературе этот способ часто именуется как метод проектов. Данный вид учебной деятельности носит исследовательский характер и включает в себя следующие этапы:

1) определение проблемы, цели и задач деятельности;

2) выдвижение гипотезы исследования;

3) обсуждение методов исследования;

4) выявление круга источников исследования;

5) план исследования;

6) выбор способа оформления результатов исследования.

Проектную деятельность целесообразно включать при выполнении больших самостоятельных заданий. Например, при изучении раздела «Имя существительное» учащимся предлагается проектное задание: «Улицы моего города».

1. Учащиеся должны собрать названия улиц своего города.

2. Собранные названия необходимо сгруппировать по принципу: признак, положенный в основу названия улищьл.

3. Проследить, менялись ли названия улиц. Чем были обусловлены эти изменения?

4. Ученики должны попытаться сделать вывод об особенностях мировоззрения жителей города по склонности выбирать те или иные признаки называния.

5. Оформить результаты своего исследования в виде небольшого доклада.

Таким образом, методика формирования культурно-языковой компетенции актуализирует эвристический подход в учебном процессе и основывается на принципе продуктивного образования, указывающего на то, что качество образования определяется не столько полнотой изучения известной информации, сколько уровнем приращения к ней нового, качеством созданного учениками образовательного продукта. Разрабатываемая методика включает разнообразные формы эвристического обучения: эвристический урок, эвристическое погружение, проектную деятельность, задания по интерпретации языковых фактов, эксперименты с культурно маркированными единицами, моделирование, 
сопоставление явлений разных языков, написание сочинений на лингвокультурологические темы. В ходе выполнения заданий может быть использован ряд приёмов: приём вживания, комментирования внутренней формы знаков, гиперболизации, выдвижения гипотезы, анализа различных точек зрения. Рассмотренные приёмы придают процессу обучения осмысленный характер, блокируют у учащегося стереотип, что новая информация не нужна.

\section{Литература}

1. Хуторской А. В. Эвристическое обучение : теория, методология, практика : [научное издание] / А. В. Хуторской. - М. : Международная педагогическая академия, 1998. - 266 с. 